First Peoples Child \& Family Review

A Journal on Innovation and Best Practices in Aboriginal Child Welfare Administration,

\title{
Aboriginal Youth Talk about Structural Determinants as the Causes of their Homelessness
}

\section{Cyndy Baskin}

Volume 3, Number 3, 2007

URI: https://id.erudit.org/iderudit/1069395ar

DOI: https://doi.org/10.7202/1069395ar

See table of contents

Publisher(s)

First Nations Child and Family Caring Society of Canada

\section{ISSN}

1708-489X (print)

2293-6610 (digital)

Explore this journal

Cite this article

Baskin, C. (2007). Aboriginal Youth Talk about Structural Determinants as the Causes of their Homelessness. First Peoples Child \& Family Review, 3(3), 31-42. https://doi.org/10.7202/1069395ar

\section{Article abstract}

This article explores structural determinants as possible causes of the homelessness of Aboriginal youth in Toronto, Ontario, Canada. It includes a brief literature review and provides some of the findings of a recent research project, which implemented an Aboriginal research methodology with homeless youth in Toronto. These findings point to a strong link between Aboriginal children growing up in poverty and involvement in child welfare and becoming homeless as youth. Suggestions for positive change at the policy level are offered in order to prevent the next generation of Aboriginal children growing up to become homeless youth.
This document is protected by copyright law. Use of the services of Érudit (including reproduction) is subject to its terms and conditions, which can be viewed online.

https://apropos.erudit.org/en/users/policy-on-use/ 


\title{
Aboriginal Youth Talk about Structural Determinants as the Causes of their Homelessness
}

\author{
Cyndy Baskin ${ }^{\mathrm{a}}$
}

${ }^{a}$ Associate Professor, School of Social Work, Ryerson University, ON, Canada

\section{Introduction:}

This article, which is based on a research project, explores the structural factors that may have led to the homelessness of Aboriginal youth in an urban centre. It begins with definitions of homelessness, then examines the prevalence of homelessness for Aboriginal youth and next turns to a brief discussion of colonization and the role of child welfare in this process. The article then reports on the findings of the project that was conducted with homeless Aboriginal youth in Toronto using a culture-based research methodology.

This research project was conducted by myself as the principal investigator and a youth who is currently attending university as the research assistant. I am of Mi'kmaq and Irish descent and a professor in a school of social work. The research assistant is a young, Ojibway woman with a social work degree who is now in law school. We are both active participants in Toronto's Aboriginal community and have many relatives who have been/are homeless youth and who have had involvement with child welfare.

Author Notes: Chi meegwetch to Lori Mishibinijima, the research assistant on this project, the youth workers who helped to set it up and the inspiring youth who participated. I hope I get to sit in future research circles with you.

Questions or correspondence concerning this article may be addressed to:

\section{cbaskin@ryerson.ca}

\begin{abstract}
This article explores structural determinants as possible causes of the homelessness of Aboriginal youth in Toronto, Ontario, Canada. It includes a brief literature review and provides some of the findings of a recent research project, which implemented an Aboriginal research methodology with homeless youth in Toronto. These findings point to a strong link between Aboriginal children growing up in poverty and involvement in child welfare and becoming homeless as youth. Suggestions for positive change at the policy level are offered in order to prevent the next generation of Aboriginal children growing up to become homeless youth.
\end{abstract}

Toronto was chosen as the site for this research project as both the principal investigator and research assistant reside there and have connections to several Aboriginal agencies that service youth. In addition, Toronto has a large Aboriginal population and represents many diverse Nations (Statistics Canada, 2003). The medicine wheel was selected as the research methodology for the project after consulting with Aboriginal youth workers and youth themselves. They confirmed that the majority of youth were familiar with the medicine wheel and it is a teaching tool used by many Nations such as the Cree and Ojibway.

While there does appear to be some overlap between Eurocentric models of structural determinants and those presented by Aboriginal scholars (DuHanmel, 2003; Thomas, 2003), such as education, income and diet, this article proposes that to adequately address determinants faced by Aboriginal youth, a framework that is culturally appropriate and addresses colonization needs to be implemented. It further proposes that an arm of colonization which is 
likely related to homelessness among youth is their involvement in state institutional child welfare (Cauce \& Morgan, 1994; Fall \& Berg, 1996; Fitzgerald, 1995; Lindsey, et al, 2000; Maclean et al.,1999).

Current research on Aboriginal youth is minimal, especially in the area of homelessness. Available statistics do not illustrate the extent of the problem, although most advocates suggest that the rate of homelessness for this population is dramatically increasing (Abrahams, 2000; United Native Nations Society, 2001). The purpose of this research project, then, was to explore with homeless Aboriginal youth the conditions under which they became homeless, how they may be assisted today and what can be done to prevent homelessness from continuing in the future. The significance of this project is connected to the fact that Aboriginal youth are the fastest growing group in Canada while the non-Aboriginal population is aging (Hick, 2007; Hoglund, 2004; Statistics Canada, 2003). It asserts that it will become increasingly important to Canada's future, especially in terms of our workforce, to ensure that Aboriginal youth be healthy and productive members of society. This article contributes suggestions for change to social policies and direct practice focusing on control of child welfare by and with Aboriginal peoples.

\section{Definitions}

Common definitions of homelessness include people that live on the street, stay in emergency shelters, spend more of their income on rent or live in crowded conditions which keeps them at serious risk of becoming homeless (Golden, et al, 1999). The Toronto Disaster Relief Committee (1998) states that homelessness means simply not having secure housing.

This committee expands on the definition by contending that homelessness "means being exiled from the mainstream patterns of day-to-day life" (para.5). Canadian federal New Democratic Party leader Jack Layton (2000) describes homelessness as socially constructed. In particular, he contends that homelessness is usually defined to fit a specific political agenda, or certain stereotypes, which eventually becomes the definition in the eyes of the public.

The United Native Nations Society (UNNS) of British Columbia, which is one of the provincial organizations of the Congress of Aboriginal Peoples that advocates for the inherent rights of Aboriginal peoples (2001), states that Aboriginal homelessness includes "those who have suffered from the effects of colonization and whose social, economic, and political conditions have placed them in a disadvantaged position" (20). The UNNS (2001) acknowledges that there is a high rate of Aboriginal peoples at risk of homelessness and, therefore, the effects of colonization should be included as a major part of an Aboriginal specific definition.

With particular attention to youth, homelessness is usually defined as those youth aged 15-24 who are not living with a family in a home, or not in the care of child protection agencies. Homeless youth are also described as those living "in an unsafe or temporary living environment" (Fitzgerald, 1995, 7). The Canadian Mortgage and Housing Corporation (2001) and Golden et al. (1999) describe homeless youth as those youth with no permanent address.

\section{Prevalence}

Many sources state that there is no accurate data regarding homeless Aboriginal peoples, let alone Aboriginal youth (Golden et al., 1999; Layton, 2000; Native Counseling Service of Alberta, 2000; UNNS, 2001). In Layton's Homelessness: The Making and Unmaking of a Crisis (2000), what statistics exist show that Aboriginal peoples in general do have a high rate of homelessness as compared to the rest of Canadian society. The NCSA (2000) states that "the Aboriginal homeless rate is at about $40 \%$ Canada wide" (3). Golden et al. (1999), in their major report for the City of Toronto, reports that Aboriginal peoples make up $15 \%$ of the homeless population in Toronto and that "many Aboriginal Canadian youth from reserves and urban communities end up on the streets of Toronto" (75). If this 15\% figure is correct, it means that Aboriginal peoples are overrepresented in the homeless population by more than a factor of three considering they make up only $4.4 \%$ of the Canadian population (Statistics Canada, 2001).

It is also important to note that the rate of homelessness is usually derived from the number of people who use shelters. However, the UNNS (2001) indicates that shelter users do not represent the entire Aboriginal homeless population as many do not utilize the shelter system. Furthermore, the Aboriginal community is estimated to have a high rate 
of concealed homelessness and these numbers are not included in the official data. This category includes those in transition homes, jails and detox centres, and those who live in overcrowded, unstable, or inadequate housing. It also includes "couch surfing," which is when people stay at a friend or family members' dwelling for a short period of time, then move on to another persons' home. Another category that often goes unnoticed is those who are at high risk of becoming homeless. This category includes many Aboriginal peoples who live in poor housing conditions and pay more than $25 \%$ of their income for rental accommodations. Therefore, to completely capture the Aboriginal homeless population, all of these categories of homelessness must be included (UNNS, 2001).

It is also significant to note that Aboriginal youth are the fastest growing segment within the Canadian population. In the 1996 census, Aboriginal peoples constituted $3.8 \%$ of the population, while in the 2001 census this figure rose to $4.4 \%$. The median age for non-Aboriginal peoples was 37.7 while Aboriginal peoples had a median age of 24.7. The birth rate for Aboriginal peoples was also 1.5 times higher than for non-Aboriginal peoples. This population will continue to grow because, currently, $33 \%$ of the Aboriginal population is under age 14, as opposed to only $19 \%$ of non-Aboriginal peoples (Statistics Canada, 2003). Similarly, Castellano (2002) found that over $50 \%$ of the Aboriginal population is under 25. Thus, not only is there a high rate of Aboriginal specific homelessness, but there may be a substantially higher rate of youth homelessness within this population given the demographics.

\section{Factors Associated with Homelessness}

Within the literature, the most frequently cited cause of homelessness for all peoples in Canada is lack of affordable housing (Golden et al., 1999; Hulchanski, 2004; Shapcott, 2001; TDRC, 1998). Some authors (UNNS, 2001; Weinreb et al., 1998) argue that personal factors, such as fetal alcohol spectrum disorder, addictions, poverty, poor health, and/or dysfunctional family relations, are the cause of Aboriginal homelessness. Other literature states that socio-economic status and the lack of resources on reserves are also causes of homelessness (Beavis et al., 1997).
However, UNNS (2001) argues that even what appear to be personal factors are in fact the effects of structural barriers. UNNS (2001) states that the homelessness of Aboriginal peoples is rooted in "structural factors such as unemployment, low wages or lack of income, loss of housing, colonization, racism, discrimination (systemic or otherwise), patriarchy, cultural and geographic displacement, and the reserve system" (p.2). Other authors contend that the historical introduction of foreign systems such as education, justice, health and child protection have left Aboriginal peoples in a "cycle of economic dependency, including high rates of poverty and unemployment" (Morrissette et al, 1993, p.94).

Based on the literature outlined above, we assert that the factors associated with homelessness are connected to the omnipresent concept of colonization. Colonization did not only create the relationship between Aboriginal peoples and mainstream society it is also experienced personally. Thus, we emphasize that the history of colonization and its current impacts explains, in large part, why some Aboriginal peoples are homeless in their own lands. We also believe that a framework which addresses the negative impacts of colonization on Aboriginal peoples and emphasizes our strengths needs to be developed. A Eurocentric lens fails to do this as it tends to frame Aboriginal peoples as social and economic disadvantages to the rest of Canadian society while negating our political power.

\section{Institutional Child Protection}

The distinctive factor between homeless adults and homeless youth is that the latter are forced to leave home at an early age, before they have a chance to fully develop into healthy adults (Cauce \& Morgan, 1994; Fitzgerald, 1995; Golden et al., 1999; MacLean et al, 1999). In general, many youth that are homeless come from the care of the child protection system such as adoptive homes, foster homes or group homes (Cauce \& Morgan, 1994; Fall \& Berg, 1996; Fitzgerald, 1995; Lindsey et al, 2000; Maclean et al., 1999). According to one study, between $25 \%$ and $50 \%$ of homeless youth were previously in the care of foster homes (Lindsey et al., 2000). This may be connected to the fact that these systems are designed to care for young children (under 15), so youth encounter barriers to service because they are 
too old for children's services and not old enough for adult services. Therefore, they are often left with no choice but to live on the street (Fitzgerald, 1995).

The child protection system, historically a tool of colonization, continues to the present day (Anderson, 1998; Du Hamel, 2003; Hudson, 1997; McKenzie \& Seidl, 1995; Report of the Aboriginal Justice Inquiry of Manitoba, 1998). Although there have been some Aboriginal child welfare agencies developed throughout Canada (Anderson, 1998; Hudson, 1997; McKenzie \& Seidl, 1995), Aboriginal children are still over represented in the child protection system (Hudson, 1997; Mckenzie \& Seidl, 1995; Thomas, 2003). This may be due to the restrictions placed on Aboriginal child welfare organizations. These organizations do have some control over the policies and procedures within their agencies, however, they are still usually required to comply with federal and provincial laws and policies. As researchers in the area of Aboriginal child welfare, Bennett, Blackstock and De La Ronde (2005) write:

Up to this day, provisions in both federal and provincial legislation dictate how child welfare will be governed, administered, and, often, delivered by the over $120+$ Aboriginal Child and Family Services Agencies in Canada. This would not be so controversial if the provincial and federal systems were meeting the needs of Aboriginal children and youth but the evidence overwhelmingly indicates that the current legislation, policy and practice of child welfare are not making meaningful differences in supporting the well-being of Aboriginal children and youth. The question is thus raised why Canadian governments have not recognized tribal authority that sustained child well-being for millennia (45).

For anyone to take an institution such as child welfare that has left a challenging legacy for many Aboriginal peoples and turn it into something appropriate for Aboriginal communities is an enormous task. Yet it is obviously the goal of Aboriginal child protection services. As Hoglund (2004) advocates, both research and policies developed within an Aboriginal context by Aboriginal peoples is crucial because:

Understanding how contextual mechanisms foster as well as challenge Native children's healthy social development is essential for generating informed, strengths-based research priorities and supporting Native sponsored policy and program development ... Researchers, educators, service providers, and policymakers need to look beyond Western European models of successful development to adequately understand favoured socialization and developmental processes within the sociocultural, historical, political, legal and socioeconomic contexts of Native children's lives and the families and communities in which Native children live (165 \& 168).

We stress that insider views are necessary in order to develop social policies that reflect Aboriginal worldviews and values. Thus, this research project explored the following questions with insiders - Aboriginal youth affected by homelessness:

- What is appropriate parenting within Aboriginal perspectives?

- What supports do Aboriginal parents, families and communities need to raise children?

- How does prevention become a priority?

- How do we frame "neglect" within the realities of poverty?

\section{Aboriginal Youth Research Circles}

In this research project with Aboriginal youth, which we (and an Aboriginal student research assistant) designed and conducted, one research circle took place at two youth programs within Toronto that service youth who are homeless or at risk of becoming so. A total of 24 youth participated. Basic information was obtained from the participants through a standard form that all of the youth filled out. Next, within the research circles, youth were invited to discuss specific areas about their past and current situations. They were free to decide for themselves which areas they wanted to contribute to. The research methodology was based on Aboriginal cultural protocols and integrated a tool known as the "Medicine Wheel" as shown below:

The youth were from a variety of Nations across Canada, however, the majority were of Ojibway and Cree descent. Approximately one fourth were Ojibway and another one fourth were Cree. There were also youth who had mixed Aboriginal heritage in their Nations, again approximately one fourth. About sixty-two per cent of the participants were male. None of the participants identified as transgendered 


\section{First Peoples Child \& Family Review, Volume 3, Number 3, 2007}

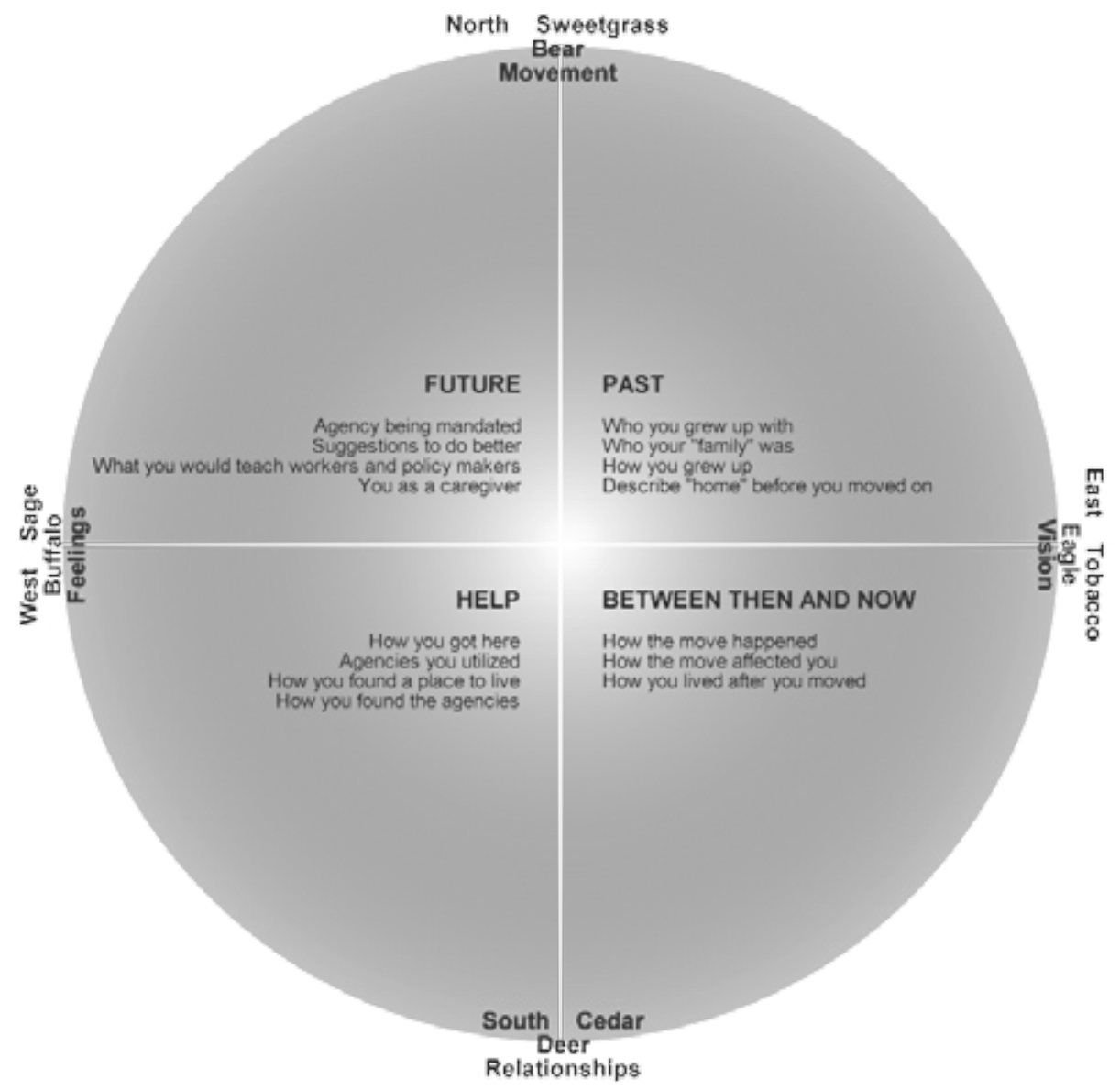

or transsexual. The majority of the youth reported as heterosexual. One youth reported being Two Spirited (gay, lesbian or bisexual). The age range spanned ten years from fifteen to twenty-five.

The youth participants were from many diverse towns and reserve communities across Canada, from Alberta to New Brunswick. The major trend in the place of origin was that three quarters of the participants were originally from reserve communities. The remainder were from small towns in northern areas of the country. Few participants were from large urban centres, and only one was born in Toronto. The length of time they had lived in Toronto also varied with some living here for eleven days and others for twenty years. At the time of this project, just over one third of the participants lived with a relative. Only four youth had lived in the same place for more than one year. The rest of the twenty youth had lived at their current address for less than a year. Thus, there was a dominant trend of temporary living conditions with the youth who participated in this project.

Sixteen youth had completed grades eight through eleven. This illustrates that many of the youth had a high incompletion rate for academic studies. This is especially significant considering that many of the participants were in their early twenties. One particular question on the information form was "what grade are you currently completing?" Six youth answered they were not completing any grade at the time and they had not completed grade twelve (needed for a high school diploma). This shows that in this group of Aboriginal youth in their early twenties, many have not completed high school and were not in the process of doing so. Of twenty four youth, only three were currently completing a college education and none were attending university. This information demonstrates a great need for more comprehensive educational resources and greater access to education that addresses the worldviews and needs of Aboriginal youth. 


\section{Eastern Direction: Looking Back}

The first topic raised with the youth was "who they grew up with." It was suggested to them that they talk about who their family was/is, how they grew up, and what were their homes like before they moved on. Most of the youth stated that they grew up in the care of the Children's Aid Society (CAS), which included foster homes and group homes. More than half of all of the respondents mentioned having to relocate more than once. Those that stated they relocated said they moved to and from several different families and in some cases these homes or families were spread across the country. Four youth mentioned being in trouble with the law, were incarcerated, or always "getting into trouble." Seven youth mentioned living in a lone parent female headed family. Two of the youth lived with their mother, but later moved in with their father. One participant stated that he lived with his grandparents for awhile. Only two youth stated that they lived in two parent families - one of whom was later placed in the care of CAS. Hence, only one of the twenty four participants had lived with both parents for a significant amount of time. Many of the participants had also moved back and forth between their biological families and foster care while growing up.

The predominant theme in the youths' profiles is that the majority were not living with their biological parents. The responses of the youth illustrates that many of them did not have what mainstream society considers as the "traditional" family. This in itself is not negative. What is negative is the fact that many of the youth were in the care of the state and placed in unstable homes meaning that they resided with families or in group homes where they experienced psychological, emotional, physical, sexual and spiritual abuse, neglect and acts of racism (eg. one female youth was given the nickname of "squaw" in her foster home). Those who lived in lone parent families also lived with an element of instability. Many moved from home to home, both biological and otherwise, without consistency in their lives.

\section{Southern Direction: Between Then and Now}

Youth were invited to talk about the move from their "homes" into homelessness and how they lived after this move. The responses of the youth were varied. Each had a different story to tell. Some came to Toronto with their caregivers or relatives to look for work or obtain an education. One youth was passing through Toronto, but experienced a crisis and was forced to stay. One stated that her adoptive parents were abusive which forced her to move out on her own. She stated that the street life was easier because she could make her own rules. Although this life was preferable in comparison to her home life, it was tough living on the streets. Resources were difficult to access because of her young age. One participant stated that she was "sick of group homes...too many rules" and that she was constantly moving from one group home to another. Two other participants explained how they lost their apartments due to lack of funds. Some of the youth that were in care, adopted, or in group homes stated that they lived in small towns and experienced a great deal of overt racism. They had believed that they could escape this by moving to a multicultural city like Toronto. A few youth explained how they were just released from jail, and how they were often in and out of jail. Three youth stated that they came to Toronto for opportunities; they wanted to change their lives around.

The major theme in these stories illustrates that growing up in the care of, or being involved long term with, CAS - whether that be adoptive homes, foster homes, group homes or moving between biological and foster families - is often a profoundly negative experience. When asked about the reasons for moving back and forth between biological and foster homes, youth explained that when a biological parent complied with the demands of child welfare, such as staying in counseling for a long enough time period or attending a substance abuse treatment program, they were able to go back to these parents. However, when the parent stopped complying by starting to drink again or getting back with an abusive partner, the child would once again go to a foster home.

In a number of ways, this response on the part of child welfare authorities can be linked to looking at Aboriginal parents only through a Eurocentric lens. Often when Aboriginal parents are placed in a position of complying with demands to get their children back into their care, intentionally or not, it is a set up for failure. For example, they may not be voluntarily participating in programs, these programs may not be relevant in terms of examining structural reasons for their situations or they may not be culturally applicable, there may not be enough emphasis on support of and resources for the parent or the values 
and worldviews of Western society are being applied to Aboriginal parents which skews assessments.

Few of the youth who participated in this project experienced a positive home life. Many participants felt that they were forced to leave their homes. This was explained as, for example, not being wanted any longer by adoptive parents because they were rebelling, getting into trouble or questioning the rules. Even though some expressed how difficult street life was, none of them regretted their decisions for this was better than what they left behind. Among other things, this demonstrates that interventions need to be implemented before youth feel forced to leave their homes.

\section{Western Direction: Help Along the Journey}

The next area youth were asked to discuss was how they were able to receive help from social services agencies and how they were able to find a place to live once in Toronto. Some youth explained that they asked other Aboriginal peoples they did not know where they could stay for the night. Other youth stated that their friends or family members informed them of Aboriginal agencies in Toronto. One mentioned walking by a building that had an Aboriginal logo painted on the front, so he walked in. Four youth said that they were referred to an Aboriginal agency by mainstream organizations that service youth. Most of the participants agreed that they felt more comfortable at an Aboriginal agency. However, they also stated that it was good to get served by both Aboriginal and mainstream agencies. There were a few who expressed some dislike for certain Aboriginal organizations because of their experiences there regarding other peoples' behaviours such as intoxication and violence, but they still utilized them.

For the most part, the youth expressed a great sense of community amongst themselves, both within youth programs and on the streets. They spoke about helping each other out by sharing information about resources, agencies and service providers within Toronto that were considered to be non-judgemental of them and some of their behaviours, such as substance using. Many youth talked about sticking together when on the streets for greater protection from both other people on the street and the police and letting others know about safe places to sleep. When they had something to share, whether that be money, alcohol, cigarettes or food, they tended to share it with other youth. Some of them referred to each other as brothers and sisters even though they were not related by blood. They also shared secrets, stories, emotions and laughter.

\section{Northern Direction: Looking Towards the Future}

The participants then explored what they would do to make the system better for future youth. They talked about what they would like to teach social workers and policy makers, especially with regards to the child protection system. To put this in context for themselves, the youth chose an Aboriginal child and family services agency becoming mandated as a child protection authority as an example to discuss what they would like social workers and policy makers to know. There were mixed feelings from the youth about the agency's change from offering voluntary services to taking on the responsibility of child protection. Many youth felt that bringing an Aboriginal perspective to child protection was vital. Others felt that it was a negative move because, in their opinions, the Aboriginal agency was too concerned with minor issues. One youth gave the example that "[a worker from the agency] stripped my kids because they had diaper rashes." Another young mother stated that the agency forced traditional ways on her, when she just wanted some emotional support. Another youth stated that other Aboriginal services were just as likely to involve child protection and related the example of an Aboriginal day care centre calling the Aboriginal child protection agency because her child had a "running nose." Some youth felt that the Aboriginal agency is "too quick to jump on rumours." Some of the participants who made these comments about the agency also expressed dislike for mainsteam CAS, saying that they often felt like they were under "a microscope" and that they did not believe that child protection - either mainstream or Aboriginal -- would be so cautious with older adults. Thus, they felt like they were being discriminated against specifically because they were Aboriginal youth.

Although some youth disagreed with Aboriginal family services agencies becoming mandated, their suggestions for change did express some common themes. One raised a great difficulty with child protection stating that children have to be protected, but at the same time, Aboriginal families have different needs that are often neglected by these services. Next, 
they talked about the importance of incorporating Aboriginal culture into the lives of youth, no matter who their families are. The majority of the youth agreed that even though Aboriginal family services becoming mandated is an empowering concept, it does not work if these services have to use the same legislation as mainstream CAS. Although mandated Aboriginal child welfare agencies employ Aboriginal peoples as workers to varying degrees and incorporate some practices such as involving extended families as care givers of children, they must follow the same legislation - the Child and Family Services Act in Ontario - as all other mandated child welfare authorities. This Act is not inclusive of Aboriginal values, particularly around collective responsibilities for raising children, nor does it acknowledge the impacts of colonization or the inherent strengths of Aboriginal peoples and communities. It does not make clear distinctions between neglect and poverty nor does it include aspects of prevention which is crucial to the well being of the future of our children and youth. In keeping with these points, some youth spoke about how mainstream Canadian society decides what is acceptable child rearing for Aboriginal peoples and this is where the conflict lies. Other participants expressed that there is a need for more Aboriginal policy makers to change child welfare legislation or the cycle of oppression will continue. They explained that if this is not done, then it will simply mean "putting a brown face on it" [Aboriginal control of child welfare]. They further explained that this may "soften the blow" for some, but continue to oppress many.

The youths' suggestions about the need for more Aboriginal policy makers and changing child welfare legislation is brilliant. Since the current Child and Family Services Act does not address the sovereignty of Aboriginal peoples, what is necessary then is an Aboriginal Family and Child Services Act. Such an Act could address many of the concerns that the youth raised in this research project. For example, it would be developed by Aboriginal peoples according to our definitions of family, child care and parenting, This Act could clearly differentiate between poverty and neglect. It would reflect the values of Aboriginal peoples such as collective responsibility for children, communal sharing of resources and assisting families when they are struggling rather than taking their children away from them. Perhaps most importantly, an Aboriginal Family and Child Services Act would recognize the impacts of colonization upon all of us and focus our resources, both human and financial, on the well being of everyone in our communities and on the prevention of further internalized oppression which leads to the harm of all.

The next major issue that youth discussed was the policies governing who is allowed to be a customary care (foster) or adoptive parent and how these need to be transformed to better fit the circumstances of Aboriginal peoples. First, youth concurred that permanency planning should be key, ensuring that workers try to keep children with family members. Another point was to have more customary care homes and adoptive families in reserve communities. Overall, the youth expressed their belief that there must be more Aboriginal families willing to adopt or care for children, and that the government needs to encourage and support this process through funding and legislation. Some of the examples they introduced were that some Aboriginal families may not have a lot of money, but that should not be a deciding factor in caring for children. They pointed out that many lower income families can do a good job of raising children. Furthermore, the youth took the stand that if being poor is such a concern, then the government should provide the necessary funds to foster families. They adamantly stated that, after all, the government is the reason why so many Aboriginal peoples are living in poverty in the first place. Moreover, these youth believe that preference should not be given to two parent families. Many Aboriginal families are headed by one parent who can raise children in a positive environment. Youth also stated that, if non-Aboriginal families are going to take in Aboriginal children, it needs to be mandatory that the children be connected to their cultures. They also believe that more effort needs to be put into keeping siblings together if families have to place their children into care. However, all of the youth were adamant that keeping families together must be of the greatest importance. One promising suggestion made to help keep families was that there could be a group of parents that can be used as an information resource for other parents who need it during times when they struggle with raising their children.

The participants also addressed the issue of child protection workers. They suggested that workers should be Aboriginal or, if not, have intensive 
training on issues affecting Aboriginal peoples. They stressed the need for greater consistency in training and education for helpers and how workers need to take into account what the client wants. They want workers to realize that everyone is different and what is "normal" for an Aboriginal family may not be "normal" for a mainstream one.

In conclusion, the theme for youth regarding the future was that for real positive change to occur, adding in a few cultural pieces is not enough, but rather legislation and social policies have to be completely changed to better suit the needs of Aboriginal families.

\section{Coming Full Circle: Analysis}

The depth of analysis these young people demonstrate both in terms of their knowledge and understanding of the reasons for their homelessness, and the critical lens from which they view the world is amazing. They are insightful and articulate. They call it the way they see it and no one is fooling them.

These youth were easily able to comprehend their life experiences, which were for the most part contact with child protection and separation from their biological families and home communities, within the realities of colonization and oppression. A comment that stands out most perhaps is from a young man who said, "mostly we're taken away by child welfare because of poverty and this translates into neglect by them." For Aboriginal peoples, poverty is a direct result of colonization which destroyed the original economic basis of our communities. In contemporary society, breaking out of poverty is, in large part, dependent on acquiring formal education and employment. However, education has been historically genocidal and is currently alienating for many Aboriginal peoples so that $68.5 \%$ of youth do not complete high school (Hick, 2007: RCAP, 1996). According to the RCAP report, both youth and parents are adamant that education does not prepare them for life in understanding themselves as Aboriginal peoples nor does it prepare them for life in the modern world. In fact, according to this report, youth stated they left school because they were made to feel ashamed of being Aboriginal, they experienced racism and there was no recognition of Aboriginal perspectives in history or respect for their cultures.
Certainly, low educational attainment affects peoples' future employment and income levels. However, according to the results of a study conducted by Kunz, Milan and Schetagne (2000), Aboriginal peoples also have difficulty finding employment because of racism in the work place. They found that compared to white Canadians, Aboriginal peoples with university degrees are less likely to have managerial and professional jobs. In addition, they are over represented in the bottom $20 \%$ and under represented in the top $20 \%$ of income earners. Even with the same level of higher education, white Canadians are three times as likely as Aboriginal peoples to be in the top $20 \%$ of income earners. These results are confirmed by Hick (2007) as well. Clearly, these studies reveals that even with university degrees, job opportunities are out of reach for many Aboriginal peoples.

Unlike the generation before them, this group of youth usually has a roof over their heads at night. But they do not have homes. Thanks to Aboriginal agencies that service youth, most of these young people are housed and have access to some health services. However, most struggle with poverty, have not completed high school, are transient, and, in the case of many female youth, are single mothers involved with child welfare who are often concerned that their children will be removed from them. This concern seems to come from a belief in the tendency for social service workers to "blame the victim" (Anderson, 1998; Hudson, 1997; Thomas, 2003). Even within Aboriginal child welfare agencies, internalized oppression has caused some Aboriginal peoples to believe the negative stereotypes about some members of their community and thus they treat them just as the dominant society does.

From a structural perspective, for the most part Aboriginal child protection agencies continue to be mandated to operate within the framework of legislation and social policies not based on Aboriginal values and perspectives. Since these policies do not incorporate the distinct needs of Aboriginal peoples, a major focus needs to be creating legislation and policies that are compatible with Aboriginal worldviews in general while taking into consideration the great diversity of our Nations. In addition to this, the legislation and policies must also take into account past injustices and the effects they have on the health 
and behaviours of Aboriginal peoples today. To simply add in "culturally based practice" without any change to oppressive legislation is clearly detrimental for it changes little (Anderson, 1998; Hudson, 1997; RAJIM, 1998).

Furthermore, mainstream legal and political discourses regarding self-government, Aboriginal rights and treaties are grounded in Western constructions of nationhood that originate from European history and cultures. Such discourses inevitably marginalize Aboriginal worldviews in the construction of nationhood in self-government and treaty negotiations. This approach, then, continues to entrench Eurocentric-Canadian structural power imbalances rather than creating positive economic, political and social change for Aboriginal peoples. I emphasize that until constructs of nationhood can be examined from both an Aboriginal and a Eurocentric lens equally, self-government that creates inclusive and sustainable Aboriginal communities is impossible.

The preliminary work from this research project also has many encouraging messages. These youth are greatly concerned about the next generation. When they spoke about their experiences and recommendations, they did not do so in ways that will necessarily benefit them, but rather because they hope to make contributions to the future of both their children and all Aboriginal children in general. These youth also view positive change as centring on re-structuring child welfare legislation and social policy. They identified that change simply by creating Aboriginal child protection agencies with Aboriginal workers is not enough.

Aboriginal child and family services agencies are to be commended for picking up the responsibility of child welfare and attempting to incorporate traditional knowledges into their work. However, many colonial legacies have been passed on to their shoulders, such as internalized oppression, family violence, poverty and suicide, which they are expected to heal. They also must face unrealistic expectations placed upon them by both the Aboriginal communities they serve and mainstream society and governments (Hudson \& Taylor-Henley, 1995; Bennett, Blackstock \& De La Ronde, 2005). Aboriginal peoples, including those who work in the area of child welfare, must re-claim the knowledge that prior to colonization, we lived as autonomous groups and our inherent right to self-determination - which included controlling the affairs affecting our families and children - was never abdicated despite the policies and actions forced upon us by Canadian governments (First Nations Child and Family Task Force, 1993; Association of Native Child and Family Services Agencies of Ontario, 2001; Bennett, Blackstock \& De La Ronde, 2005). Aboriginal responsibility and control must go beyond child welfare service delivery to the creation of legislation and policies that will restore traditional forms of government. This is crucial since present legislation and social policies related to child welfare are based on Eurocentric values and worldviews, thereby making them an ongoing tool of colonization. Hence, as the youth raised, Aboriginal peoples must become policy makers in this area. Without significant changes to social policies, the major request to keep families together and concentrate heavily on prevention, which one youth described as "eliminating poverty", cannot possibly happen.

According to the voices of this group of youth, holistic good health rests largely on the value of supporting families through equitable access to resources to care for the well being of their children. Such resources include inclusive education that is representative of Aboriginal youth, job opportunities based on merit and anti-colonial, anti-racist policies and legislation all of which aim to eliminate poverty caused by colonization.

\section{Expanding The Circle: Future Research}

This paper reflects the responses of only twenty four youth and so it cannot be said that they are representative of homeless Aboriginal youth in Toronto. Further research needs to be conducted. This preliminary work can be used as a template in terms of the Aboriginal research methodologies implemented and the framework for examining the structural causes of homelessness for Aboriginal youth. Thus, these templates can be incorporated into future projects involving more youth in Toronto, other cities in Ontario and urban centres across Canada. The implications of this project provide evidence that Aboriginal research methodologies are legitimate ways of conducting research with youth, that colonization lies at the root of social ills such as homelessness and that state intervention in the lives of Aboriginal families must end in order to realize 
self-determination and self-government. In order for radical social change to occur, it must become unacceptable that Aboriginal peoples are homeless in their own homeland.

A few youth workers, several Aboriginal agencies that work with homeless youth, and some of the youth themselves have indicated a strong interest in being involved with a larger research project as partners. Thus, the findings from this project are being used to submit research proposals to possible funders for future research which would include both

Aboriginal students and other youth as research assistants. In this way, these youth will have the opportunity to develop research skills while making significant contributions to this work. Their goal of creating a better world for the next generation is possible.

\section{References}

Abrahams, P. (2000). The Toronto report card on homelessness 2000. Toronto, Ontario, Canada: City of Toronto. Retrieved online May 15, 2004 from: http://www.city.toronto.on.ca/homelessness/2000/ index.htm.

Anderson, K. (1998). A Canadian child welfare agency for urban Natives: The clients speak. Child Welfare, 77, p. 441 - 461.

Association of Native Child and Family Services Agencies of Ontario (July 2001). Pre-Mandated Native Child and Family Service Agencies: Issues and Recommendations. Thunder Bay, ON: The Association.

Beavis, M., Klos, N., Carter, T., \& Douchant, C. (1997). Literature review: Aboriginal peoples and homelessness. Winnipeg, Manitoba, Canada: Institute of Urban Studies. Retrieved online May 15, 2004 from: http://www.ginsler.com/ documents/f aborig.html.

Bennett, M., Blackstock, C. \& De La Ronde, R. (2005). A Literature Review and Annotated Bibliography on Aspects of Aboriginal Child Welfare in Canada. Ottawa, ON: The First Nations Research Site of the Centre of Excellence for Child Welfare and the First Nations Child \& Family Caring Society of Canada. Retrieved online May 15,
2004 from: http://www.fncaringsociety.ca/docs/ AboriginalCWLitReview_2ndEd.pdf.

Canadian Mortgage and Housing Corporation (2001). Environmental scan on youth homelessness. Ottawa, Ontario, Canada: CMHC.

Castellano, M. (2002). Aboriginal family trends: Extended families, nuclear families, families of the heart. Ottawa, Ontario, Canada: The Vanier Institute of the Family.

Cauce, A., \& Morgan C. J. (1994). Effectiveness of intensive case management for homeless adolescents: Results of a three month follow-up. Journal of Emotional and Behavioural Disorders, 2, p. 219-227.

Du Hamel, P. (2003). Aboriginal youth: Risk and resilience. Native Social Work Journal, 5, p. 213-224.

Fall, K. A., \& Berg, R.C. (1996). Behavioural characteristics and treatment strategies with homeless adolescents. Individual Psychology, 52, p. 431-440.

First Nations Child and Family Task Force (November 1993). Children First, Our Responsibility: Report of the First Nations Child and Family Task Force. Winnipeg: Queen's Printer.

Fitzgerald, M. D. (1995). Homeless youth and the child welfare system: Implications for policy and Service. Child Welfare, 74, p. 717-731.

Golden, A., Currie, W. H., Greaves, E. \& Latimer, E. J. (1999). Taking responsibility for homelessness: An action plan for Toronto. Toronto, Ontario, Canada: City of Toronto.

Hick, S.(2007). Socialwelfare in Canada: Understanding income security. Toronto: Thompson Educational Publishing Inc.

Hoglund, W.L. (2004). Navigating discrimination: The interplay of contexts on Native children's social development. In Nelson, C.A \& Nelson, C.A. (Eds.) Racism, eh? A critical inter-disciplinary anthology of race and racism in Canada (p. 153171). Concord, Ontario, Canada: Captus Press Inc.

Hudson, P. (1997). First Nations child and family services: Breaking the silence. Canadian Ethnic Studies, 29 (3), p. 161 - 173. 
Hudson, P. \& Taylor-Henley, S. (1992). Interactions Between Social and Political Development in First Nations Communities. Winnipeg, MN: University of Manitoba, Faculty of Social Work.

Hulchanski, D. (2004). Question and answer: Homelessness in Canada. Retrieved online May 15, 2004 from: http://www.tdrc.net.

Kunz, Milan \& Schetagne (2000). Unequal Access: A Canadian Profile of Race Differences in Education, Employment and Income. Toronto: Canadian Race Relations Foundation.

Layton, Jack. (2000). Homelessness: The making and unmaking of a crisis. Toronto, Ontario, Canada: Penguin.

Lindsey, E. W., Kurtz P. D., Jarvis, S., Williams, N. R., \& Nackerud, L. (2000). How runaway and homeless youth navigate troubled waters: Personal strengths and resources. Child and Adolescent Social Work Journal, 17, p. 115-140.

Maclean, M. G., Embry, L. E., \& Cauce, A. M. (1999). Homeless adolescents paths to separation from family: Comparison of family characteristics, psychological adjustment, and victimization. Journal of Community Psychology, 27, p. 179-187.

Mckenzie, B., \& Seidl, E. (1995). Child and family service standards in First Nations: An action research project. Child Welfare, 74, p. 633-653.

Morrissette, V., McKenzie, B., \& Morrissette, L. (1993). Towards an Aboriginal model of social work practice. Canadian Social Work Review, 10(1), p. 91-108.

Native Counseling Services of Alberta [NCSA]. (2000). Community consultation on homelessness report. Edmonton, Alberta, Canada: NCSA. Retrieved online May 15, 2004 from: http:// www.edmonton-omelessness.ca/aboriginal/ consultation.doc.

Report of the Aboriginal Justice Inquiry of Manitoba. (1998). The justice system and Aboriginal people. Winnipeg, Manitoba, Canada: Manitoba Government. Retrieved online May 15, 2004 from: http://www.ajic.mb.ca/volumel/chapter14. $\underline{\mathrm{html}}$.

Royal Commission on Aboriginal Peoples (1996). Volume 1, Looking Forward, Looking Back. Ottawa, ON: Canada Communication Group.
Shapcott, M. (2001). Housing, homelessness, poverty and free trade in Canada. Retrieved online May 15, 2004 from: http://www.tdrc.net.

Statistics Canada. (2003). 2001 census analysis series: Aboriginalpeoples of Canada, ademographicprofile. Retrieved online May 15, 2004 from: http://www12. statcan.ca/english/census01/Products/Analytic/ companion/abor/pdf/96F0030XIE2001007.pdf.

Thomas, W. (2003). The social determinants of Aboriginal health: A literature review. Native Social Work Journal, 5, p. 270-286.

Toronto Disaster Relief Committee [TDRC]. (1998). State of emergency declaration. Retrieved online May 14, 2004 from http://www.tdrc.net. ("Resources" section).

United Native Nations Society [UNNS]. (2001). Aboriginal homelessness in British Columbia. Retrieved online May 15, 2004 from: http://www. urbancenter.utoronto.ca/pdfs/elibrary/UNNS Aboriginal Homelessn.pdf. 